\title{
Synthesis of potential related compounds of Cefdinir
}

\author{
Korrapati. V. V. Prasada Rao, ${ }^{a}$ Ramesh Dandala, ${ }^{a^{*}}$ Ananta Rani, ${ }^{a}$ and Andra Naidu ${ }^{b}$ \\ ${ }^{a}$ Chemical Research Department, APL Research Center, Hyderabad-500 072, India \\ ${ }^{b}$ J. N. T. University, Kukatpally, Hyderabad-500 072, Andhra Pradesh, India \\ E-mail: rdandala@aurobindo.com
}

\begin{abstract}
The synthesis of three contaminants of Cefdinir (1), formed during the preparation of Cefdinir bulk drug, is described. The products identified as (6R, 7R)-7-[(Z)-2-(2-aminothiazol-4-yl)-2hydroxyiminoacetamido]-8-oxo-3-vinyl-5-thia-1-azabicyclo [4.2.0] oct-2-ene-2-carboxylic acid5-oxide (2), (6R, 7R)-7-[(Z)-2-(2-aminothiazol-4-yl)-2-hydroxyiminoacetamido]-8-oxo-3-vinyl5-thia-1-azabicyclo [4.2.0] oct-3-ene-2-carboxylicacid (3) and (6R, 7R)-7-[(Z)-2-(2aminothiazol-4-yl)-2-hydroxyiminoacetamido]-8-oxo-3-methyl-5-thia-1-azabicyclo [4.2.0] oct2-ene-2-carboxylic acid (4).
\end{abstract}

Keywords: 7-AVNA, Cefdinir, pharmaceuticals, synthesis, contaminants

\section{Introduction}

Cefdinir 1 is [ $5 y n-7-$ [2-(2-aminothiazole-4-yl)-2-hydroxyiminoacetamido]-3-vinyl-3-cephem-4carboxylic acid]. It is a third generation cephalosporin antibacterial drug for oral administration. ${ }^{1}$ The most remarkable future of Cefdinir is the excellent activity against staphylococcus species. ${ }^{2}$ Several methods are reported in the literature for the preparation of Cefdinir ${ }^{3-7}$, but the related compounds were not discussed. However, the degradation kinetics of cefdinir has been cited in the literature. ${ }^{8}$ The preparation of these three contaminants has been necessary for the preparation of reference compounds for the quality control of bulk drugs and drug formulations, and pathways have been developed starting from the parent Cefdinir $\mathbf{1}$.

\section{Results and Discussion}

Cefdinir was prepared, starting from 7-amino-3-vinyl-3-cephem-4-carboxylic acid 5 by acylating with compound 6 followed by hydrolysis with base (Scheme 1). During the analysis of different batches of Cefdinir, three unknown impurities 2, 3 and $\mathbf{4}$ were detected whose area percentage 
ranged from $0.05 \%$ and $0.15 \%$. A comprehensive study has been carried out to synthesize these impurities.

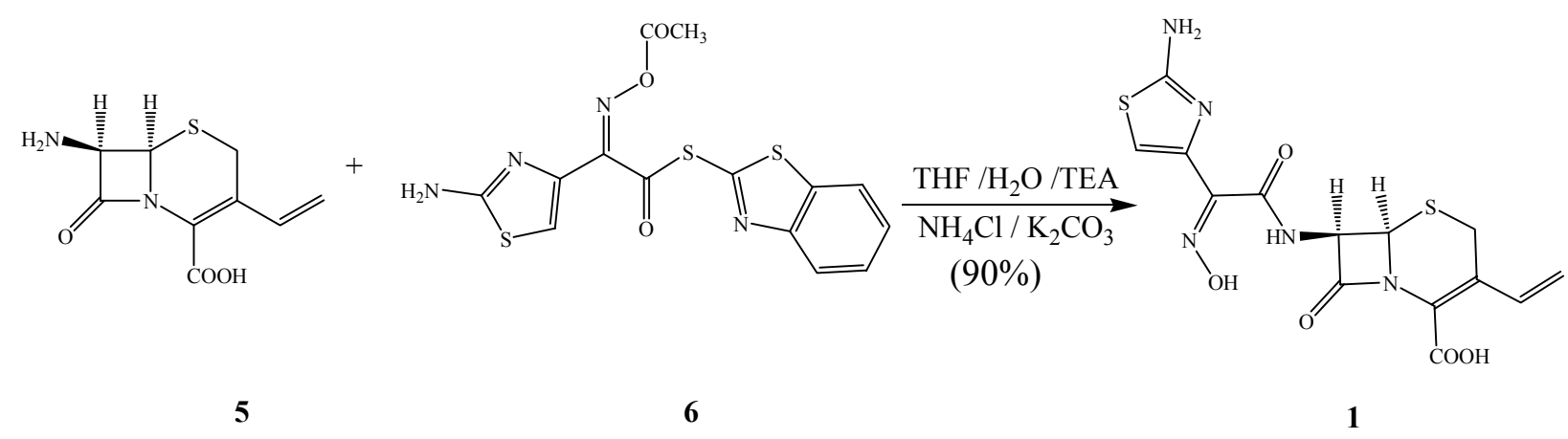

\section{Scheme 1}

Sulfoxides are very common impurities in cephalosporin antibacterial compounds. The elimination of these compounds was very difficult from the finished products. Cefdinir sulfoxide 2 was observed up to $0.1 \%$ in most of the Cefdinir batches prepared in the laboratory. Therefore it was necessary to synthesize the sulfoxide in pure form for the validation of this impurity in the Cefdinir bulk drug. Cefdinir sulfoxide was prepared by the oxidation of Cefdinir in $30 \%$ yield by using per acetic acid as an oxidizing agent (Scheme 2).

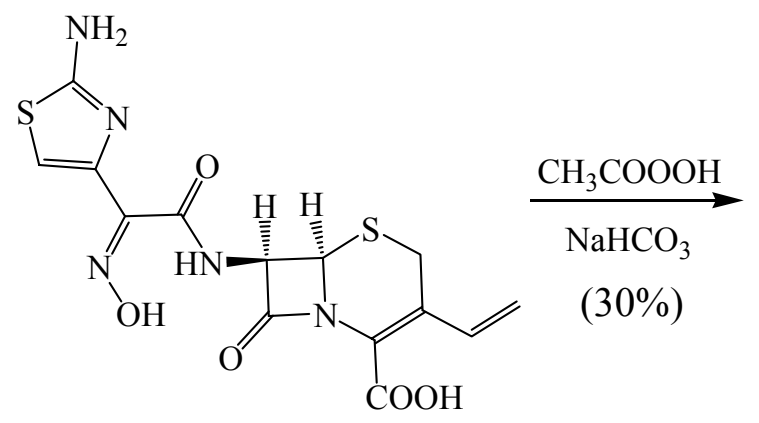

1

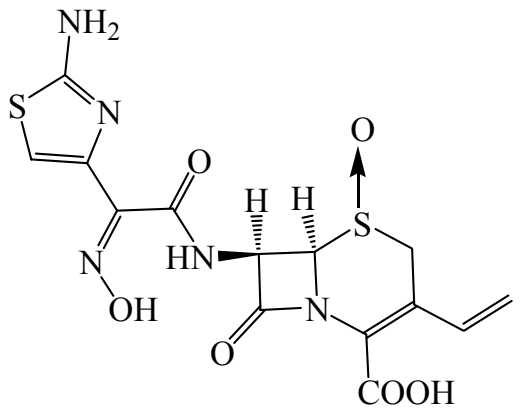

2

\section{Scheme 2}

Treating the silylated Cefdinir 1 with triethylamine in methylene chloride provided a more selective approach for the preparation of delta-2 Cefdinir 3. During the monitoring by HPLC, $60 \%$ of delta- 2 Cefdinir was formed, which was further purified by acid-base treatment to obtain compound 3 in $48 \%$ yield. (Scheme 3 ). 


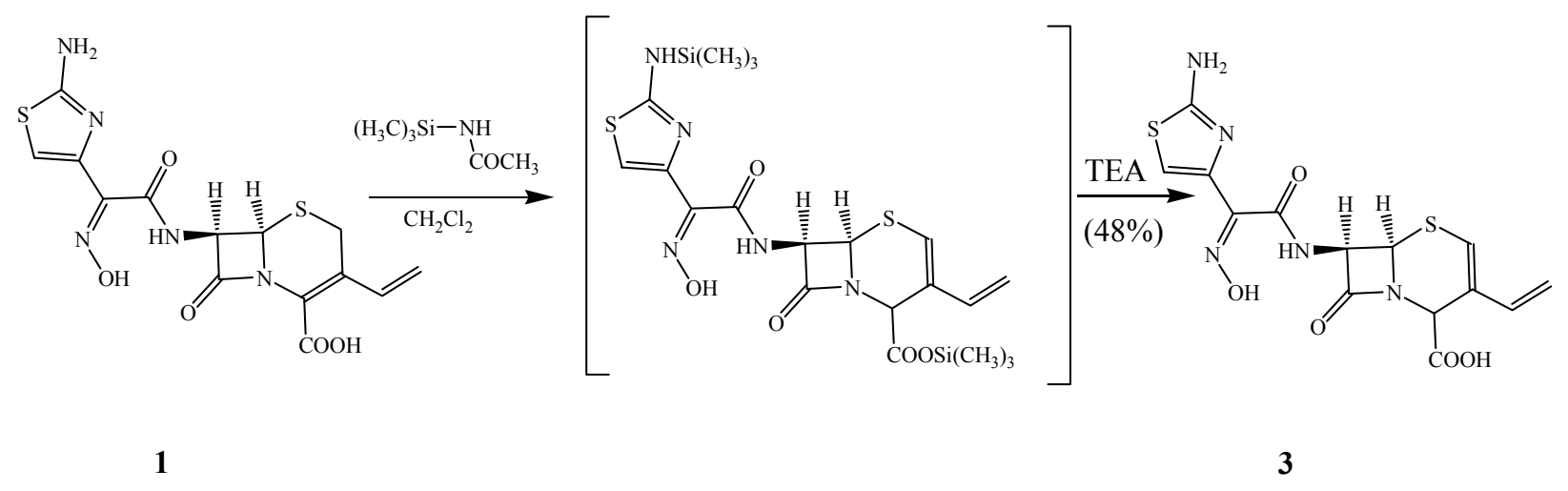

Scheme 3

Compound 4 was formed due to presence of desacetoxycephalosporanic acid 7 as an impurity in the key raw material 7-aminio-3-vinyl-3-cephem-4-carboxylic acid 5. Compound 4 was prepared in $80 \%$ yield by the acylation of compound 7 with compound 6 followed by basic hydrolysis. (Scheme 4).

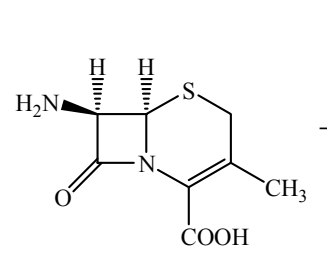

7<smiles>CC(=O)O/N=C(/Sc1nc2ccccc2s1)c1csc(N)n1</smiles>

6

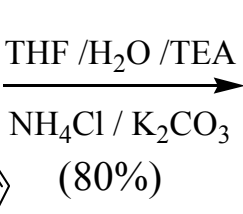

$(80 \%)$

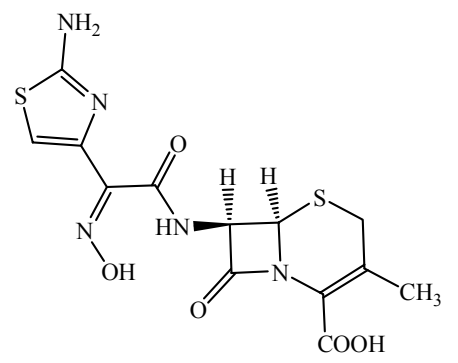

4

\section{Scheme 4}

\section{Conclusions}

A procedure has been described for the preparation of three new impurities formed during the preparation of Cefdinir bulk drug in quite good yield and purity.

\section{Experimental Section}

General Procedures. All melting points were determined with a Palmon melting point apparatus. ${ }^{1} \mathrm{H}-\mathrm{NMR}$ and ${ }^{13} \mathrm{C}$ NMR analysis were recorded on a Bruker $300 \mathrm{MHz}$ and $75 \mathrm{MHz}$ spectrometer respectively. Chemical shifts are reported in ppm downfield from TMS as internal standard. Mass spectra were measured on Perkin Elmer PE SCIEX-API 2000 mass spectrometer. 
Analytical HPLC ${ }^{9}$ were run with Hypersil BDS C18 column with the dimension of 150 X4.6 mm i.d (Thermo-Electron) at $254 \mathrm{~nm}$.

syn-7-[2-(2-Aminothiazole-4-yl)-2-hydroxyiminoacetamido]-3-vinyl-3-cephem-4-carboxylic acid (1). (Z)-2-(2-Aminothiazol-4-yl)-2-acetoxyiminothioacetate, 6 (138.38 g, $0.366 \mathrm{~mol})$ was added to a suspension of 7-amino-3-vinyl-3-cephem-4-carboxylic acid, 5 (75.0 g, 0.331mol) in tetrahydrofuran $(750 \mathrm{ml})$ under nitrogen atmosphere. DM Water $(375 \mathrm{ml})$ was added to the resulting suspension at $15-20^{\circ} \mathrm{C}$ in $10-15 \mathrm{~min}$. Thereafter triethylamine $(36.75 \mathrm{~g}, 0.363 \mathrm{~mol})$ was added in $30 \mathrm{~min}$ at $18-20^{\circ} \mathrm{C}$ and stirred the reaction mass for $5 \mathrm{~h}$ at the same temperature. Methylene chloride $(750 \mathrm{ml})$ was added followed by DM water $(375 \mathrm{ml})$ and stirred the reaction mass for $10 \mathrm{~min}$. The aqueous layer was separated and washed with methylene chloride (375 $\mathrm{ml})$. The aqueous layer was degassed under reduced pressure to remove the traces of solvents. $\mathrm{pH}$ of the aqueous layer was adjusted to 8.0 and ammonium chloride $(0.953 \mathrm{~mol})$ was added. Thereafter $20 \%$ potassium carbonate was added by maintain the $\mathrm{pH} 8.0-8.20$ at $20-25^{\circ} \mathrm{C}$ in 30 min. After potassium carbonate addition stirred the reaction mass for another $10 \mathrm{~min} . \mathrm{pH}$ was adjusted to 5 with $10 \% \mathrm{v} / \mathrm{v}$, aqueous sulfuric acid $(100 \mathrm{ml})$ at $20-25^{\circ} \mathrm{C}$. Thereafter temperature was raised to $35-40^{\circ}$ and $\mathrm{pH}$ adjusted to $2.5-2.6$ with $10 \%$ aqueous sulfuric acid $(100 \mathrm{ml})$. The solid was filtered and washed with water $(750 \mathrm{ml})$ and dried, to yield $\mathbf{1}(118.0 \mathrm{~g}, 90 \%)$ as a pale yellow solid; purity $99 \%$ (by HPLC); mp $180-190^{\circ} \mathrm{C}$ (decompose) (lit, ${ }^{7} 180-187^{\circ} \mathrm{C}$ ); IR (KBr, $\left.\mathrm{cm}^{-1}\right): 3302,3176,1784,1668,1611,1429,1545,1350,1334,1050,1017 ;{ }^{1} \mathrm{H}-\mathrm{NMR}(300 \mathrm{MHz}$, DMSO-d $\left._{6}\right) \delta 3.55 \& 3.83(\mathrm{ABq}, 2 \mathrm{H}), 5.19(\mathrm{~d}, 1 \mathrm{H}), 5.30(\mathrm{~d}, 1 \mathrm{H}), 5.60(\mathrm{~d}, 1 \mathrm{H}), 5.79(\mathrm{dd}, 1 \mathrm{H}), 6.67$ $(\mathrm{s}, 1 \mathrm{H}), 6.80-6.90(\mathrm{~m}, 1 \mathrm{H}), 7.10(\mathrm{bs}, 2 \mathrm{H}), 9.50(\mathrm{~d}, 1 \mathrm{H}), 11.33(\mathrm{~s}, 1 \mathrm{H}) ;{ }^{13} \mathrm{C}-\mathrm{NMR}(75 \mathrm{MHz}$, DMSO-d $_{6}$ ) 24.1, 58.6, 59.5, 108.4, 118.6, 125.7, 126.0, 132.6, 143.9, 149.0, 164.0, 164.6, 164.8, 169.2; MS (ESI, $m / z)$ : $396.2[\mathrm{M}+\mathrm{H}]^{+}$. Anal. Calcd. For $\mathrm{C}_{14} \mathrm{H}_{13} \mathrm{~N}_{5} \mathrm{O}_{5} \mathrm{~S}_{2}: \mathrm{C}, 42.49 ; \mathrm{H}, 3.29 ; \mathrm{N}$, 17.70; S, 16.19. Found: C, 42.33; H, 3.28, N, 17.63, S, $16.17 \%$.

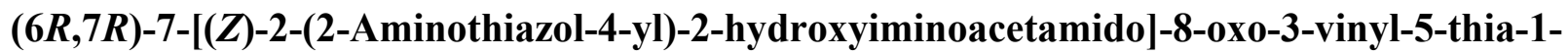
azabicyclo [4.2.0] oct-2-ene-2-carboxylic acid -5-oxide (2). Sodium bicarbonate (3.6 g, 0.0379 mol) was added to a suspension of syn-7- [2-(2-aminothiazole-4-yl)-2-hydroxyiminoacetamido]3-vinyl-3-cephem-4-carboxylic acid, 1 (10 g, $0.0253 \mathrm{~mol})$ in $30 \mathrm{~min}$ at $10-15^{\circ} \mathrm{C}$ and stirred for 30 min to get a clear solution. The resulting solution was cooled to $2-5^{\circ} \mathrm{C}$ and $30 \% \mathrm{w} / \mathrm{w}$, per acetic acid $(7.03 \mathrm{~g}, 0.0277 \mathrm{~mol})$ was added in $30 \mathrm{~min}$ at $2-5^{\circ} \mathrm{C}$. Thereafter stirred the reaction mixture for $2 \mathrm{~h}$ at the same temperature. $\mathrm{pH}$ was adjusted to 2.8 with $10 \% \mathrm{w} / \mathrm{w}$ sulfuric acid and stirred for $1 \mathrm{~h}$. The reaction mass was diluted with water $(200 \mathrm{ml})$. The solid was filtered and washed with water and dried to yield 2 (3.1 g, 30\%) as an off-white solid. mp $177-182^{\circ} \mathrm{C}$ (decompose); IR $\left(\mathrm{KBr}, \mathrm{cm}^{-1}\right): 3320,3150,2900,1777,1666,1633,1425,1525,1303,1115,1023 ;{ }^{1} \mathrm{H}-\mathrm{NMR}$ $(300 \mathrm{MHz}$, DMSO-d $) \delta 3.55 \& 4.29(2 \mathrm{~d}, 2 \mathrm{H}), 5.04(\mathrm{~d}, 1 \mathrm{H}), 5.34 \& 5.60(2 \mathrm{~d}, 2 \mathrm{H}), 5.98(\mathrm{dd}, 1 \mathrm{H})$, $6.81(\mathrm{~s}, 1 \mathrm{H}), 7.08(\mathrm{dd}, 1 \mathrm{H}), 7.30$ (brs, $2 \mathrm{H}), 8.59$ (d, $1 \mathrm{H}), 11.67$ (brs, $1 \mathrm{H}) ;{ }^{13} \mathrm{C}-\mathrm{NMR}(75 \mathrm{MHz}$, DMSO-d $_{6}$ ) 43.4, 58.8, 67.0, 108.0, 118.6, 120.3, 125.4, 133.2, 143.1, 148.4, 163.3, 163.9, 164.5, 169.2; MS (ESI, $m / z)$ : $412.2[\mathrm{M}+\mathrm{H}]^{+}$. Anal. Calcd. For $\mathrm{C}_{14} \mathrm{H}_{13} \mathrm{~N}_{5} \mathrm{O}_{6} \mathrm{~S}_{2}: \mathrm{C}, 40.87 ; \mathrm{H}, 3.18 ; \mathrm{N}$, 17.02; S, 15.59. Found: C, 40.90; H, 3.20, N, 17.03, S, $15.60 \%$. 


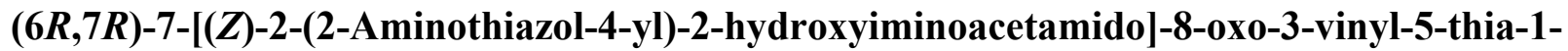
azabicyclo [4.2.0] oct-3-ene-2-carboxylic acid (3). N-trimethylsilylacetamide (19.90 g, 0.152 mol) was added to a suspension of syn-7- [2-(2-aminothiazole-4-yl)-2-hydroxyiminoacetamido]3-vinyl-3-cephem-4-car-boxylic acid, 1 (20 g, $0.0506 \mathrm{~mol})$ in methylene chloride (200 ml) and stirred for $30 \mathrm{~min}$ to get a clear solution. The resulting solution was cooled to $2-5^{\circ} \mathrm{C}$ and triethylamine $(5.63 \mathrm{~g}, 0.0557 \mathrm{~mol})$ was added in $30 \mathrm{~min}$ at $2-5^{\circ} \mathrm{C}$. Thereafter stirred the reaction mixture for $24 \mathrm{~h}$ at $25-30^{\circ} \mathrm{C}$ temperature. Water $(200 \mathrm{ml})$ was added and stirred for $10 \mathrm{~min}$. The aqueous layer was separated and washed with methylene chloride $(50 \mathrm{ml})$. The aqueous layer was cooled to $2-5^{\circ} \mathrm{C}$ and $\mathrm{pH}$ adjusted to $3.0 \mathrm{with} 10 \% \mathrm{w} / \mathrm{w}$ sulfuric acid $(10 \mathrm{ml})$. The resulting slurry was stirred for $2 \mathrm{~h}$. The solid was filtered and washed with water and dried to yield $12.5 \mathrm{~g}$ $(62.5 \%)$ of 2 as a yellow amorphous powder. This solid was suspended in water $(200 \mathrm{ml})$ and $\mathrm{pH}$ adjusted to 7.5-8.0 with aqueous sodium bicarbonate at $20-25^{\circ} \mathrm{C}$ to get a clear solution. Carbon $(1 \mathrm{~g})$ was added and stirred for $30 \mathrm{~min}$. Carbon was filtered washed with water $(25 \mathrm{ml})$. The filtrate was cooled to $5-10^{\circ} \mathrm{C}$ and $\mathrm{pH}$ adjusted to 3.0 with $10 \% \mathrm{w} / \mathrm{w}$ sulfuric acid. The solid was filtered, washed with water $(50 \mathrm{ml})$ and dried to yield $3(6 \mathrm{~g}, 48 \%)$ as an off-white solid. $\mathrm{mp}$ 255-260 ${ }^{\circ} \mathrm{C}$ (decompose); IR (KBr, cm $\left.{ }^{-1}\right)$ : 3300, 3196, 3000, 1760, 1674, 1614, 1401, 1533, 1370, 1310,1113, 1046; ${ }^{1} \mathrm{H}-\mathrm{NMR}\left(300 \mathrm{MHz}, \mathrm{DMSO}_{6}\right) \delta 4.73(\mathrm{~s}, 1 \mathrm{H}), 4.89 \& 5.35(2 \mathrm{~d}, 2 \mathrm{H})$, $5.36(\mathrm{~d}, 1 \mathrm{H}), 5.45(\mathrm{dd}, 1 \mathrm{H}), 6.27(\mathrm{dd}, 1 \mathrm{H}), 6.44(\mathrm{~s}, 1 \mathrm{H}), 6.70(\mathrm{~s}, 1 \mathrm{H}), 7.38(\mathrm{~s}, 2 \mathrm{H}), 9.42(\mathrm{~d}, 1 \mathrm{H})$, 11.61 (brs, $1 \mathrm{H}) ;{ }^{13} \mathrm{C}$ - NMR (75 MHz, DMSO-d 6 ) 53.02, 54.30, 60.20, 107.80, 111.40, 121.10, 126.60, 137.0, 144.60, 149.50, 163.40, 164.60, 169.0, 169.90; MS (ESI, m/z): $396.2[\mathrm{M}+\mathrm{H}]^{+}$. Anal. Calcd. For $\mathrm{C}_{14} \mathrm{H}_{13} \mathrm{~N}_{5} \mathrm{O}_{5} \mathrm{~S}_{2}$ : C, 42.49; H, 3.29; N, 17.70; S, 16.19. Found: C, 42.60; H, 3.32, $\mathrm{N}, 17.70, \mathrm{~S}, 16.25 \%$.

syn-7-[2-(2-Aminothiazole-4-yl)-2-hydroxyiminoacetamido]-3-methyl-3-cephem-4-carboxylic acid (4). (Z)-2-(2-aminothiazol-4-yl)-2-acetoxyiminothioacetate, 6 (19.60 g, $0.0518 \mathrm{~mol}$ ) was added to a suspension of desacetoxycephalosporanic acid, 7 (10 g, $0.0467 \mathrm{~mol})$ in tetrahydrofuran $(750 \mathrm{ml})$ under nitrogen atmosphere. DM water $(50 \mathrm{ml})$ was added followed by triethylamine $(5.19 \mathrm{~g}, 0.0514 \mathrm{~mol})$ was added in $30 \mathrm{~min}$ at $18-20^{\circ} \mathrm{C}$ and stirred the reaction mass for $5 \mathrm{~h}$ at the same temperature. Methylene chloride $(100 \mathrm{ml})$ was added followed by DM water $(50 \mathrm{ml})$ and stirred the reaction mass for $10 \mathrm{~min}$. The aqueous layer was separated and washed with methylene chloride $(50 \mathrm{ml})$. The aqueous layer was degassed under reduced pressure to remove the traces of solvents. $\mathrm{pH}$ of the aqueous layer was adjusted to 8.0 and ammonium chloride $(7.17 \mathrm{~g}, 0.134 \mathrm{~mol})$ was added. Thereafter $20 \% \mathrm{w} / \mathrm{v}$, potassium carbonate $(37 \mathrm{ml})$ was added by maintain the $\mathrm{pH} 8.0-8.20$ at $20-25^{\circ} \mathrm{C}$ in $30 \mathrm{~min}$. After potassium carbonate addition stirred the reaction mass for another $10 \mathrm{~min}$. $\mathrm{pH}$ was adjusted to 5 with $10 \% \mathrm{v} / \mathrm{v}$, aqueous sulfuric acid $(13 \mathrm{ml})$ at $20-25^{\circ} \mathrm{C}$. Thereafter temperature was raised to $35-40^{\circ}$ and $\mathrm{pH}$ adjusted to 2.5-2.6 with $10 \% \mathrm{v} / \mathrm{v}$, aqueous sulfuric acid $(12 \mathrm{ml})$. The solid was filtered and washed with water (100 ml) and dried, to yield $4(13.75 \mathrm{~g}, 80 \%)$ as an off white solid; purity 98\% (by HPLC); mp 177-182 ${ }^{\circ} \mathrm{C}$ (decompose); IR (KBr, $\left.\mathrm{cm}^{-1}\right)$ : 3297, 3200, 2980, 1760, 1658, 1622, 1400, 1534, 1380, 1365, 1015; ${ }^{1} \mathrm{H}-\mathrm{NMR}$ (300 MHz, DMSO-d 6 ) $\delta 2.02(\mathrm{~s}, 3 \mathrm{H}), 3.35 \& 3.55(\mathrm{ABq}, 2 \mathrm{H}), 5.10$ $(\mathrm{d}, 1 \mathrm{H}), 5.71(\mathrm{dd}, 1 \mathrm{H}), 6.69(\mathrm{~s}, 1 \mathrm{H}), 7.40$ (brs, 2H), $9.49(\mathrm{~d}, 1 \mathrm{H}), 11.46$ (brs, $1 \mathrm{H}) ;{ }^{13} \mathrm{C}-\mathrm{NMR}(75$ 
MHz, DMSO-d $\left.{ }_{6}\right)$ 20.3, 30.0, 58.2, 59.3, 108.1, 123.7, 131.2, 142.7, 148.6, 164.4, 169.4; MS (ESI, $m / z$ ): $413[\mathrm{M}+\mathrm{H}]^{+}$. Anal. Calcd. For $\mathrm{C}_{13} \mathrm{H}_{13} \mathrm{~N}_{5} \mathrm{O}_{5} \mathrm{~S}_{2}: \mathrm{C}, 40.72 ; \mathrm{H}, 3.42 ; \mathrm{N}, 18.27 ; \mathrm{S}, 16.73$; Found: C, 40.73; H, 3.44, N, 18.30, S, $16.80 \%$.

\section{Acknowledgements}

The authors thank the management of Aurobindo Pharma Limited, Hyderabad for permission to publish this work. The authors also thank the Analytical Research Department for their valuable contribution to this work.

\section{References and Footnotes}

1. Ternansky, R. J.; Christofer, F.; Bell, W.; Theresea, G.; Skaggs, S.; Kasher, J. Antibiot. 1993, 46, 1897.

2. Inamoto, Y.; Chiba, T.; Kamimura, T.; Takaya, T. J. Antibiot. 1988, 41, 828.

3. Takaya, T.; Hisashi, T. US. Pat 4,559,334: Chem. Abstr. 1984, 101, 130505.

4. Lee, G. S.; Chang, Y. K.; Chun, J. P.; Kho, J. H. US. Pat 6,093,814: Chem. Abstr. 1997, 127, 149040

5. Rajkumar, WO 121154: Chem. Abstr. 2002, 144, 51373.

6. Sakane, J.; Kazuo, Y. ES Pat 2,013,828: Chem. Abstr. 1993, 113, 23533

7. Takaya, T.; Shirai, F.; Nakamura, H.; Inaba, Y. US. Pat 4,935,507: Chem. Abstr. 1989, 111, 96960x.

8. Okamoto, Y.; Kiriyama, K.; Namiki, Y.; Matsushita, J.; Fujioka, M.; Yasuda, T. J. Pharmaceutical. Sciences. 1996, 85, 976.

9. HPLC analysis was carried out for compounds 1, 2, 3, 4, 5, 6 and 7. 